\title{
Evaluations of Internet of Things-based personal smart farming system for residential apartments
}

\author{
Fatin Natasya Shuhaimi, Nursuriati Jamil, Raseeda Hamzah \\ Faculty of Computer and Mathematical Sciences, Universiti Teknologi MARA, Malaysia
}

\begin{tabular}{l}
\hline \hline Article Info \\
\hline Article history: \\
Received Dec 11, 2019 \\
Revised Mar 2, 2020 \\
Accepted Apr 15, 2020 \\
\hline
\end{tabular}

\section{Keywords:}

Consumption power

DHT 11 sensor

DHT 22 sensor

Internet of Things

Smart farming

Sum of absolute difference

\begin{abstract}
Urban farming is popularly accepted by communities living in cities as they are more health-conscious and to help support the high cost of living. Unfortunately, farming takes a considerable amount of time specially to monitor the plant's growth. Therefore, smart farming using Internet of Things (IoT) should be adopted to realize urban farming. In this study, two IoT-based smart farming system designs for personal usages in a residential apartment were proposed and evaluated. As the design was meant for beginners, two utmost parameters for maintaining plant growth was evaluated, that are humidity and temperature. The humidity and temperature readings of design A using DHT 11 sensor and design B using DHT 22 sensor were recorded for 3 days and were compared against the actual humidity and temperature of the environment. After comparing the sum of absolute difference (SAD) of both designs, the implementation costs, and the consumption power, there is an inconclusive finding in terms of accuracy and costs. However, the basic design and cost of implementing a personal IoT-based smart farming system were proposed. The factors to be considered in constructing a personal smart farming system were also described.
\end{abstract}

This is an open access article under the CC BY-SA license.

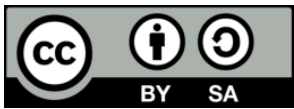

\section{Corresponding Author:}

Nursuriati Jamil,

Department of Computer Science,

Faculty of Computer and Mathematical Sciences,

Universiti Teknologi MARA,

40450 Shah Alam, Selangor, Malaysia.

Email: lizajamil@computer.org

\section{INTRODUCTION}

Smart farming is a subset of smart agriculture intended to encourage communities especially in cities to do farming in their own residential areas as the preferred means of a more environmentally friendly form of food production [1]. There are many techniques of farming in a city that include raised bed, container gardens, hydroponics, aeroponics [2], fertigation, rooftop, vertical farming, and aquaponics. Hydroponics, fertigation, aeroponics and aquaponics are types of soil less agriculture [3]. Even though these technologies showed positive potentials in agriculture, the high initial cost and the technical operational requirements [4] hinder the adoption of these technologies by individuals. Vertical farming and rooftop farming are also popular techniques of farming especially in big cities as there are many unused big walls and rooftops existing in many high-rise buildings. However, vertical and rooftop farming also require big investments and are more appropriate for landscape purposes or medium scale building owners [5]. Individuals and families living in residential apartments commonly used container gardens for small-scale farming.

Urban farming is a concept that is popularly accepted by many people living in the urban area in Malaysia to ease the burden of high cost of living [6]. If practiced correctly, urban farming can beautify a community, strengthen community ties and provide healthy food [7]. However, the hectic lifestyles of 
the urban communities deter the implementation of urban farming as maintaining and monitoring the growth of plants take substantial amount of time. Therefore, the adoption of IoT-based smart farming is becoming widespread to enable growers to optimize productivity by optimizing fertilizers, control watering usage and automating irrigation systems. Best of all, the field conditions can be monitored from anywhere at any time. Despite the advantages, IOT-based farming also has some constraints [8], particularly the initial cost of set-up. The sensors needed for raw data, the data analysts, and the implementing techniques, can prove to be too costly for an average farmer. In this paper, we propose to evaluate the cost and accuracy of setting up an IoT-based smart farming system for personal use in a residential apartment. The process of evaluating the IoT-based system can serve as guidelines for individuals who wish to set-up their own personal smart farming system. The questions that we asked include (1) How much will it cost to develop an IoT-based personal smart farming system? (2) What is the basic design of the personal smart farming system? (3) Which design is most cost-effective in terms of total cost and accuracy? Since our focus of study is the cost and accuracy of the basic IoT-based design of smart farming, the scope of this study is limited to monitor temperature and humidity only. Moreover, a study by L. Deng et al. [9] stated that the key elements that need to be interconnected by the ecosystem of a plant are soil moisture levels, and water availability.

\section{RELATED WORKS}

The basic components of an IoT-based smart farming system are sensing systems, communications systems and data analytics [10]. The sensing systems are sensors used in the farms (or plants, in our case) to monitor the environment variables such as humidity, temperature and luminosity; and the devices or actuators such as water pumps, lightings and fans. These sensors and devices communicate with each other using either TCP-based or UDP-based communication systems. Depending on the complexity of the farming system, the end-users or farmers need a decision support system to monitor the health of the farms or to perform data analytics. Table 1 summarizes the sensing, communication and support system used by few IoT-based smart farming and general systems found in the literature. The purpose of the review was to study the common devices and sensors for the sensing system, options for the communication systems, and the features of the support system.

Table 1. Summary of selected IoT-based smart farming system

\begin{tabular}{|c|c|c|c|}
\hline Authors & Sensing systems & Communication systems & Software support system \\
\hline$[11]$ & $\begin{array}{l}\text { Arduino Uno, DHT11, (temperature and } \\
\text { humidity sensor) and light intensity sensor. }\end{array}$ & Wi-Fi, Ubidots & $\begin{array}{l}\text { Short Message Service (SMS) on } \\
\text { the mobile and email. }\end{array}$ \\
\hline [12] & Arduino Uno, DHT22 & $\mathrm{Wi}-\mathrm{Fi}$ & $\begin{array}{l}\text { N/A, Only displayed humidity on } \\
\text { LCD }\end{array}$ \\
\hline$[13][14]$ & $\begin{array}{l}\text { Arduino Uno. DHT11, DHT22 (temperature } \\
\text { and humidity sensor) }\end{array}$ & Wi-Fi, ThinkSpeak Server & Blynk mobile application. \\
\hline$[15]$ & $\begin{array}{l}\text { Raspberry Pi 3, FC-28 (soil humidity } \\
\text { sensor), MQ-135 (air quality sensor), LM- } \\
393 \text { (light intensity sensor) }\end{array}$ & $\begin{array}{l}\text { Wi-Fi, Amazon AWS T2 Micro } \\
\text { EC2 }\end{array}$ & Short Message Service (SMS) \\
\hline [9] & $\begin{array}{l}\text { Rasberry Pi 3, BH1750 (luminosity } \\
\text { measurement), DHT11, DHT22 }\end{array}$ & Wi-Fi, MQTT Server, SQL Server & $\begin{array}{l}\text { Develop web-based and mobile } \\
\text { applications for farm management. }\end{array}$ \\
\hline [10] & Arduino Uno & N/A & N/A \\
\hline [16] & ATMega2560, FC-28 & Wi-Fi, AT\&T's M2X, Cloud server & Blynk mobile application \\
\hline
\end{tabular}

As shown in Table 1, the most popular microcontrollers or general-purpose computers used in the sensing system are either Arduino Uno [11-15] or Raspberry Pi [10, 16, 17]. However, in [18] utilized Arduino ATMega2560 microcontroller for measuring and monitoring soil moisture. Raspberry Pi is obviously more sophisticated and expensive compared to Arduino-based microcontroller [19]. Since we are proposing a personal IoT system, Arduino controller was favoured as it is low-cost, can be powered using battery pack, has built-in storage and a simple interface [20]. It is also known to require low technical skill to apply [21]. Compared to Arduino ATMega2560, Uno is enough and suitable for beginners. Furthermore, upgrading to ATMega2560 is easy as all codes written for Uno is compatible with Mega, but not vice versa. Work by A. Glória et al. [22] also suggested that Arduino Uno was the best sensor node for a set of scenarios using low-cost devices, based on delay, data rate and efficiency. The sensors popularly used for measuring temperature and humidity in IoT-based system are DHT 11 and DHT 22. These sensors were used in [12-14] for monitoring the environment's temperature and humidity of crops or for general purposes. In all cases, communication of the sensors and devices used $\mathrm{Wi}-\mathrm{Fi}$ and data received were uploaded to a cloud platform if the IoT-based smart farming system is equipped with a support system. Some common cloud platforms are the AT\&Ts' M2X Cloud and Amazon's cloud. In our work, we deployed our support system using a commercial developer cloud [23]. 


\section{RESEARCH METHOD}

The basic items for an IoT-based system are the hardware platform/processor, operating system and devices, sensors and actuators, input/output devices, physical channel, logical channels, network/connectivity topology and security. Figure 1 illustrates the basic design of a personal IoT-based system. We constructed two IoT-based smart farming systems using the same design with a different humidity and temperature sensors. design A used DHT 11 sensor, while design B utilized DHT 22 sensor.

We chose to use a 2,250-tie points breadboard to tidily connect the I/O devices and actuators. Power supply for the microcontroller that is Arduino Uno was connected by an USB cable instead of a battery to get continuous and stable electricity. The LED display was used to display output and to test for any power bridge. It was preferred because of its longer lifespan, less power consumption, higher illumination, fabrication process, lower cost and more eco-friendly [24]. The components connections are shown in Figure 2. The components are the microprocessor (i.e. Arduino Uno), the temperature and humidity sensor (i.e. DHT 11/22) and the LCD. Additional components are 10k and 5k resistors to control the power from the microprocessor to the LCD and to the sensor, respectively. A 9-volts battery and two 5-volts power sources were also added to support the capacity of the components.

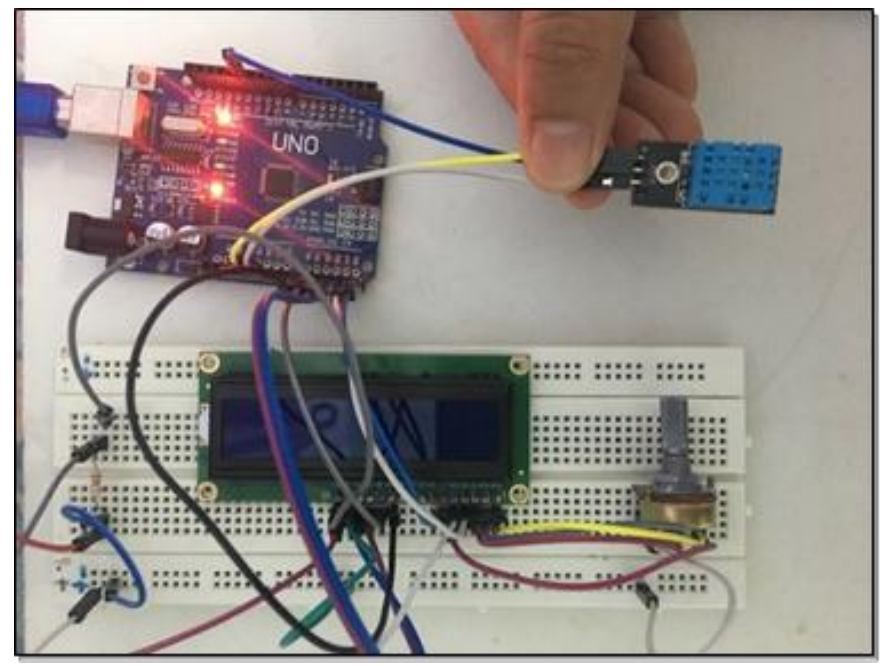

Figure 1. Basic design of an IoT-based system

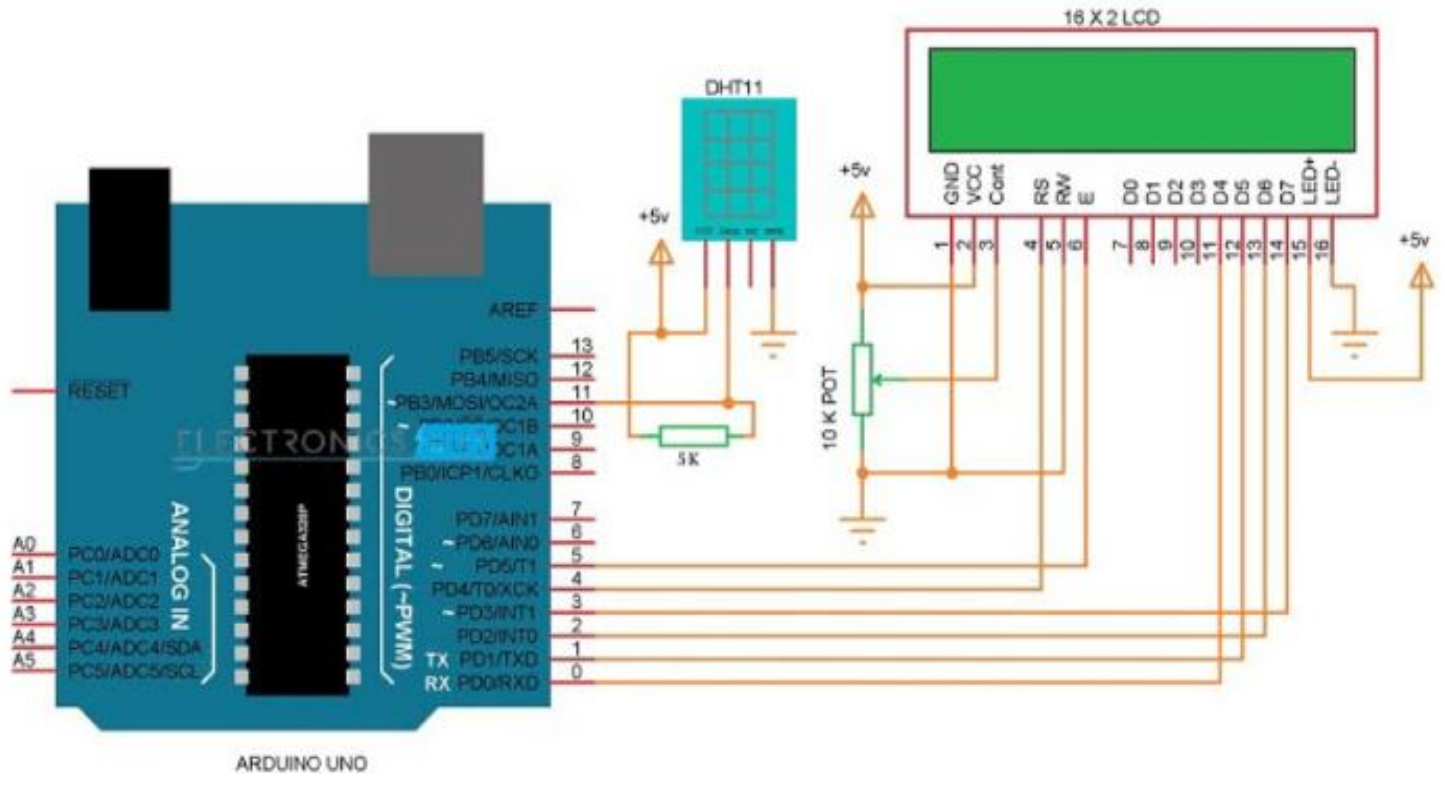

Figure 2. Integration of components in the IoT-based system 
The system was deployed for three days and data were collected from the sensors in the morning (i.e. 7 a.m., 8 a.m., and 9 a.m.) and in the evening (i.e. 5 p.m., 6 p.m., and 7 p.m.). These times were selected as they are the common times for attending plants. Since the target users are individuals staying in residential apartments, the plants were not exposed to direct sunlight and the only water source was done manually. In general, an in-house plant needs $20^{\circ}$ to $22^{\circ} \mathrm{C}$ with 80 to $90 \%$ of humidity. Therefore, we set up rules in our smart farming system as shown in the process specification in Figure 3. A sprinkler to water the plants was automatically set to $\mathrm{ON}$ state if the humidity was less than $60 \%$ or temperature was more than $24^{\circ} \mathrm{C}$. Meanwhile, the sprinkler automatically turned OFF when it reached humidity of $85 \%$ or the temperature dropped to below $15^{\circ} \mathrm{C}$.

The current humidity and temperature readings were taken from a weather app and compared to the readings captured by design A and Design B. The comparisons were done by computing the sum of absolute differences (SAD) [25] of the humidity readings to the actual readings for each design. The smaller the SAD value, the closer the sensor's humidity reading is to the actual humidity. SAD equation is shown in (1).

$$
d(x, y)=\sum_{i=1}^{n}\left|x_{i}-y_{i}\right|
$$

where $x=\left(x_{1}, x_{2}, \ldots, x_{n}\right)$ and $\mathrm{y}=\left(\mathrm{y}_{1}, \mathrm{y}_{2}, \ldots, \mathrm{y}_{\mathrm{n}}\right)$ are points in $n$-dimensional space.

Based on the costs and accuracy of the sensors, the better design of the IoT-based personal smart farming system was determined. An example of the humidity and temperature readings from design A and design B on Day 1 can be seen in Table 2. The power consumed by design A and design B was also measured to determine the cost-effectiveness of the sensors. A digital clamp meter was used to compute the total power consumptions of both designs.

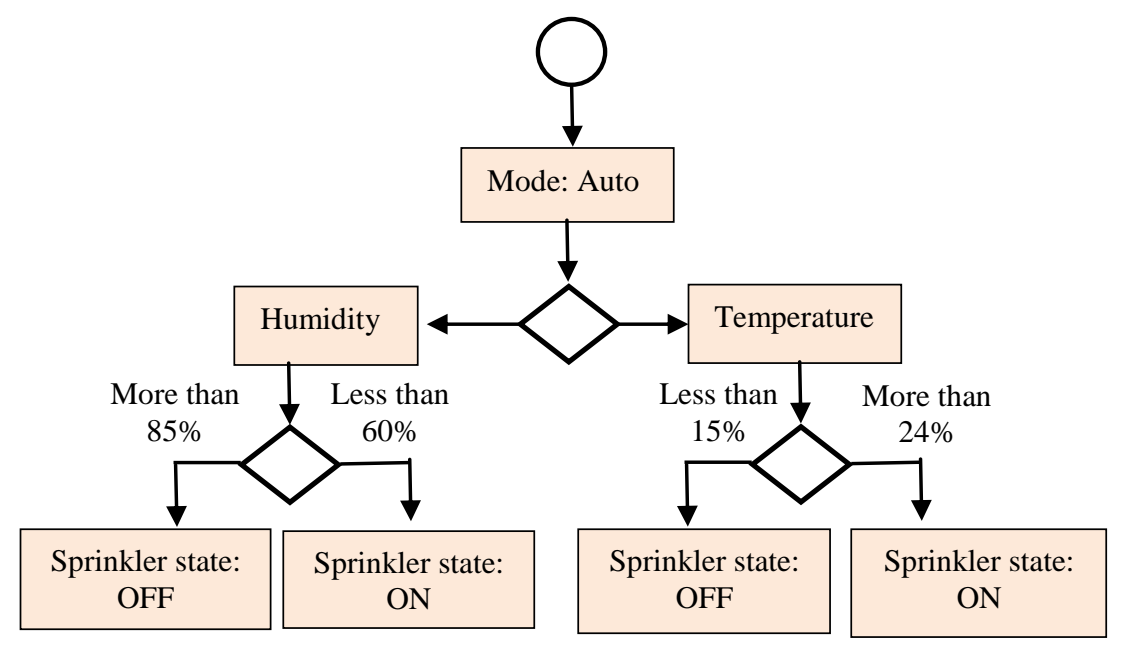

Figure 3. Process specification of the IoT system

Table 2. Readings of humidity and temperature from DHT 11 and DHT 22 sensors

\begin{tabular}{lcccc} 
Timestamp & $\begin{array}{l}\text { Design A } \\
\text { Humidity }(\%)\end{array}$ & Temperature $\left({ }^{\circ} \mathrm{C}\right)$ & $\begin{array}{c}\text { Design B } \\
\text { Humidity }(\%)\end{array}$ & Temperature $\left({ }^{\circ} \mathrm{C}\right)$ \\
\hline $\begin{array}{l}\text { 2019-12-23 } \\
\text { 07:01:00 }\end{array}$ & 79 & 25 & 90 & 25 \\
$\begin{array}{l}\text { 2019-12-23 } \\
\text { 08:01:00 }\end{array}$ & 65 & 30 & 76 & 23 \\
2019-12-23 & 69 & 37 & 65 & 28 \\
09:01:00 & & & & \\
2019-12-23 & 54 & 30 & 80 & 30 \\
$\begin{array}{l}17:: 01: 00 \\
\text { 2019-12-23 }\end{array}$ & 77 & 23 & 99 & 31 \\
$\begin{array}{l}\text { 18:01:00 } \\
\text { 2019-12-23 }\end{array}$ & 89 & 20 & 80 & 27 \\
$19: 01: 00$ & & & & \\
\hline
\end{tabular}


Figure 4 illustrates the measurement of the power consumption of the IoT system. For this study, we developed a web-based application system using RESTful web service and Ethernet Shield (ESP 8266) as a web client. The web-based application comprised an Arduino web client application that read sensor values and sent them to the web server; a PHP/MySQL application that handled the POST requests sent to the server; and a data visualization that employed JavaScript framework D3.js to display the results.

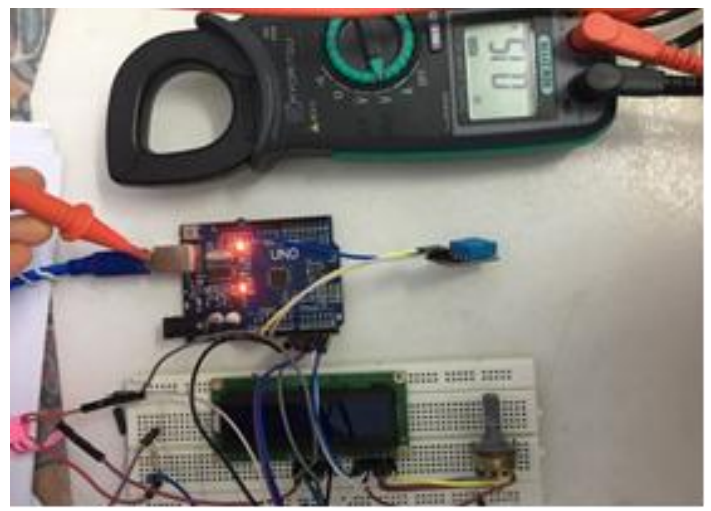

Figure 4. Measurement of the power consumption

\section{RESULTS AND DISCUSSION}

The costs of constructing design A and design B are presented in Table 3. As can be seen, the total cost for design A was MYR 61.95 and for design B was MYR 69.15. In terms of cost, design A that used DHT 11 sensor is cheaper than design B. Other than the cost of the tangible items and devices, we also measured the power consumption of each design to ensure that lower power consumption to operate the IoTbased system was used. Based on the measured power consumption using the clamp meter, design A required 15 volts, while design B needed 10 volts. In the long run, design B was favoured over design A to save operational costs.

In Table 4, readings of humidity from design A and design B were compared to find out which design closely matched the actual humidity. We averaged out the readings of 3 consecutive days at the stated 6 timestamps for both designs. We further computed the Sum of Absolute Differences as in (1). Therefore, the SAD for design A was calculated as $|92.33-90|+|73-78|+|65.66-67|+|66.66-89|+|74.66-78|+|83.33-81|$ $=37.07$. Meanwhile, the SAD for design B was $|92.33-90|+|76.66-78|+|63.33-67|+|82-89|+|87.33-78|+|83-81|$ $=25.67$. Based on the $\mathrm{SAD}$ value, design $\mathrm{B}$ is more accurate than design A for the humidity readings.

\begin{tabular}{clccc}
\multicolumn{5}{c}{ Table } \\
\hline 3o & Costs of setting up the IoT design of the smart farming \\
\hline 1 & Arduino UNO & $\begin{array}{c}\text { Price } \\
\text { (MYR) }\end{array}$ & $\begin{array}{c}\text { Design A } \\
\text { (MYR) }\end{array}$ & $\begin{array}{c}\text { Design B } \\
\text { (MYR) }\end{array}$ \\
\hline 2 & 22.00 & 22.00 & 22.00 \\
3 & LCD 16x4 & 25.00 & 25.00 & 25.00 \\
4 & 10k potentiometer & 2.40 & 2.40 & 2.40 \\
5 & Jumper wire & 3.60 & 3.60 & 3.60 \\
6 & LED & 0.05 & 0.10 & 0.10 \\
7 & 10k resistor & 0.45 & 0.45 & 0.45 \\
8 & USB cable & 3.50 & 3.50 & 3.50 \\
& Sensor & & 4.90 & 12.90 \\
\hline
\end{tabular}

Table 4. Comparisons of humidity readings between design A and design $\mathrm{B}$

\begin{tabular}{cccc}
\hline Timestamp & $\begin{array}{c}\text { Design A } \\
\text { Humidity }(\%)\end{array}$ & $\begin{array}{c}\text { Design B } \\
\text { Humidity }(\%)\end{array}$ & $\begin{array}{c}\text { Actual } \\
\text { humidity }(\%)\end{array}$ \\
\hline 07:01:00 & 92.33 & 92.33 & 90 \\
08:01:00 & 73 & 76.66 & 78 \\
09:01:00 & 65.66 & 63.33 & 67 \\
17::01:00 & 66.66 & 82 & 89 \\
18:01:00 & 74.66 & 87.33 & 78 \\
19:01:00 & 83.33 & 83 & 81 \\
\hline
\end{tabular}


The same procedures were repeated for the temperature readings. Table 5 presented the temperature readings from design $\mathrm{A}$ and design $\mathrm{B}$ as compared to the actual temperature. The $\mathrm{SAD}$ for temperature readings against the actual temperature was computed for design $\mathrm{A}$ and $\mathrm{B}$ using (1). The SAD of the temperature readings for design A was $|23.33-24|+|28-24|+|32-26|+|30.33-30|+|25.66-27|+|26.33-28|=14.01$. As for design $\mathrm{B}$, the SAD was calculated as $|21.33-24|+|26.66-24|+|30-26|+|33.66-30|+|28.33-27|+\mid 26.33-$ $28 \mid=15.99$. The $\mathrm{SAD}$ of temperature readings of design $\mathrm{A}$ is smaller compared to design $\mathrm{B}$ indicated that design A was more accurate compared to design B.

\begin{tabular}{cccc} 
Table 5. Comparisons of temperature readings between design A and design B \\
\cline { 2 - 4 } & $\begin{array}{c}\text { Design A } \\
\text { Temperature }\left({ }^{\circ} \mathrm{C}\right)\end{array}$ & $\begin{array}{c}\text { Design B } \\
\text { Temperature }\left({ }^{\circ} \mathrm{C}\right)\end{array}$ & $\begin{array}{c}\text { Actual temperature }\left({ }^{\circ} \mathrm{C}\right) \\
\text { Timestamp }\end{array}$ \\
\hline 07:01:00 & 23.33 & 21.33 & 24 \\
08:01:00 & 28 & 26.66 & 24 \\
09:01:00 & 32 & 30 & 26 \\
17::01:00 & 30.33 & 33.66 & 30 \\
18:01:00 & 25.66 & 28.33 & 27 \\
19:01:00 & 26.33 & 26.33 & 28 \\
\hline
\end{tabular}

\section{CONCLUSION}

In this paper, we evaluated the costs and accuracy of two IoT-based personal smart farming system based on the reading of temperature and humidity. For both designs, the costs of setting up the basic IoT platform was between MYR 60.00 to MYR 70.00. Depending on the sensors and actuators added to the basic platform, the cost will increase exponentially. The minimal set-up for a personal smart farming system in a residential apartment to monitor temperature and humidity was also stated in Table 3 . Watering plants at the correct time is crucial for their growth, thus these two parameters (i.e. humidity and temperature) are the basic requirements for a smart farming system. We also compared two designs of IoT platform, one using DHT 11 sensor (i.e. design A), and the other utilized DHT 22 sensor (i.e. design B). Design A is cheaper compared to design $\mathrm{B}$ and the temperature readings are more accurate than readings from Design $\mathrm{B}$. However, the power consumption of design $\mathrm{B}$ is lower than design $\mathrm{A}$ and the humidity readings of design $\mathrm{B}$ is more accurate compared to design A. Therefore, based on these results, there is no conclusive finding on the most cost-effective design of IoT-based for personal smart farming.

More investigations and criteria of a cost-effective design of an IoT-based personal smart farming system should be done in the future. In this paper, the time deployed to measure the cost-effectiveness is too short. Further experiments should be considered on more cost-effective parameters such as computational time, energy consumption and the robustness of the IoT platform.

\section{ACKNOWLEDGEMENTS}

Due acknowledgement is accorded to the Ministry of Education and Institute of Research, Management and Innovation, Universiti Teknologi MARA for the funding received through the Fundamental Research Grant Scheme-RACER, 600-IMYR I/FRGS-RACER 5/3 (081/2019).

\section{REFERENCES}

[1] R. Stewart, M. Korth, L. Langer, S. Rafferty, N. R. Da Silva, amd C. van Rooyen, "What are the impacts of urban agriculture programs on food security in low and middle-income countries?" Environmental Evidence, vol. 2, no. 1, pp 1-12, Dec. 2013.

[2] M. Armar-Klemesu, "Urban agriculture and food security, nutrition and health," Growing Cities, Growing Food: Urban Agriculture on the Policy Agenda, pp. 99-118, 2000.

[3] A. AlShrouf, "Hydroponics, aeroponic and aquaponic as compared with conventional farming," American Scientific Research Journal for Engineering, Technology, and Sciences (ASRJETS), vol. 27, no. 1, pp. 247-255, 2017.

[4] T. Tripp, "Hydroponics advantages and disadvantages: Pros and cons of having a hydroponic garden," Speedy Publishing LLC. United States of America, pp. 24-30, 2014.

[5] D. Despommier, "The rise of vertical farms," Scientific American, vol. 301, no.5, pp. 80-87, Nov. 2009.

[6] M. Zainal and S.R. Hamzah, "Urban agriculture: The role of knowledge among farmers in Malaysia," International Journal of Academic Research in Business and Social Sciences, vol. 7, pp. 77-85, 2017.

[7] S. Hallett, L. Hoagland, E. Toner, T. M. Gradziel, C. A. Mitchell, and A. L. Whipkey, "Urban agriculture: environmental, economic, and social perspectives," Horticultural Reviews, vol. 44, pp. 65-120, Sep 21, 2016.

[8] M. Bacco, A. berton, E. Ferro, C. Gennano, A. Gotta, S. Matteoli, F. Paonessa, M. Ruggeri, G. Virone, and A. Zanella, "Smart farming: Opportunities, challenges and technology enablers," 2018 IEEE IoT Vertical and Topical Summit on Agriculture-Tuscany (IOT Tuscany), pp. 1-6, May 2018. 
[9] L. Deng, K. Wang, G. Zhu, Y. Liu, L. Chen, and Z. Shangguan, "Changes of soil carbon in five land use stages following 10 years of vegetation succession on the Loess Plateau," China. Catena, vol. 171, pp. 185-192, Dec. 2018.

[10] Q. T. Minh, T. N. Phan, A. Takahashi, T. T. Thanh, S. N. Duy, M. N. Thanh, and C. N. Hong, "A cost-effective smart farming system with knowledge base," Eighth International Symposium on Information and Communication Technology, pp. 309-316, Dec. 2017.

[11] M. S. Kumar, T. R. Chandra, D. P. Kumar, and M. S. Manikandan, "Monitoring moisture of soil using low cost homemade soil moisture sensor and Arduino UNO," 2016 IEEE 3rd International Conference on Advanced Computing and Communication Systems (ICACCS), vol. 1, pp. 1-4, Jan. 2016.

[12] R. Kumar, P. maheshwary, and T. Malche, "Meteorological sensors oriented climatic condition based globally handled smart farming using Internet of Things," Proc. Of Int. Conf. on Sustainable Computing in Science, Technology and management (SUSCOM), Amity University Rajasthan, Feb 242019.

[13] J. Islam, U. Habiba, H. Kabir, K. G. Martuza, F. Akter, F. Hafiz, M. A. S. Haque, M. Hoq, and Md. A. Mannan, "Design and development of microcontroller based wireless humidity monitor," IOSR Journal of Electrical and Electronics Engineering, vol. 13, no. 2, pp. 41-46, 2018.

[14] S. Kalaiarasi, S. Gautamn, A. Behera, and M. Mewara, "Arduino based temperature and humidity sensor," Journal of Network Communications and Emerging Technologies (JNCET), vol. 8, no. 4, pp. 329-331, 2018.

[15] N. Zainal, N. Mohamood, M. F. Norman, and D. Sanmutham, "Design and implementation of smart farming system for fig using connected-argonomics," International Journal of Electrical and Computer Engineering, vol. 9, no. 6, pp. 5653-5662, Dec. 2019

[16] A. S. Radzi, M. K. Mohd F. Alif, Y. N. Athirah, A. S. Jaafar, A. H. Norihan, and M. S. Saleha, "IoT based facial recognition door access control home security system using Raspberry $\mathrm{Pi}$," International Journal of Power Electronics and Drive System (IJPEDS), vol. 11, no. 1, pp. 417-424, March 2020.

[17] R. Varghese and S. Sharma, "Affordable smart farming using IoT and machine learning," IEEE 2018 Second International Conference on Intelligent Computing and Control Systems (ICICCS), pp. 645-650, Jun. 2018.

[18] P. D. Vani and K. R. Rao, "Measurement and monitoring of soil moisture using Cloud IoT and Android System," Indian Journal of Science and Technology, vol. 9, no. 31, pp. 1-8, Aug. 2016.

[19] K. Keshamoni, "Design and architecture of wireless body area network using Android Application," International Journal of Informatics and Communication Technology (IJ-ICT), vol. 8, no. 2, pp. 71-76, Aug. 2019.

[20] M. Geddes, “Arduino Project Handbook-Second Edition,” San Francisco: No Starch Press, 2016.

[21] C. Bell, "Arduino-Based Sensor Nodes," in Beginning Sensor Networks with Arduino and Raspberry Pi, Apress, Berkeley, CA, pp. 51-96, 2013.

[22] A. Glória, F. Cercas, and N. Souto, "Comparison of communication pprotocols for low cost Internet of Things devices,” 2017 IEEE South Eastern European Design Automation, Computer Engineering, Computer Networks and Social Media Conference (SEEDA-CECNSM), pp. 1-6, Sept. 2017.

[23] "Digital ocean,” Jan 2020. [Online]. Available at: https://business.digitalocean.com/.

[24] S. Uddin, H. Shareef, A. Mohamded, M. A. Hannan, and K. Mohamed, "LEDs as energy efficient lighting systems: A detail review," 2011 IEEE Student Conference on Research and Development, pp. 468-472, Dec. 2011.

[25] C. Sammut and G. I. Webb, "Encyclopedia of machine learning," 2010 Edition, Boston: Springer, 2010. 